\title{
RESEÑAS BIBLIOGRÁFICAS
}

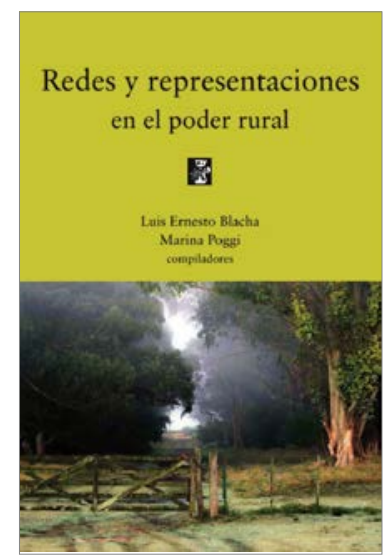

\section{Blacha Luis y Poggi Marina (comp). Redes y representaciones en el poder}

\author{
rural. Rosario, La quinta pata \& camino ediciones, 2013, pp. 300.
}

La presente compilación indaga sobre dos conceptos de gran relevancia a la hora de estudiar las dinámicas agrarias en Latinoamérica ${ }^{1}$ como son las redes y las representaciones. En ese sentido se presentan una serie de investigaciones que han puesto en dialogo diferentes actores rurales en espacios heterogéneos en donde se articulan abordajes en torno a tres ejes: poder; género y educación; y la cuestión del cooperativismo y corporativismo; atravesados por relaciones de poder y la presencia del Estado como articulador y como detentor monopólico de la violencia simbólica (Bordieu, 2014).

En el primer eje, se articulan cinco trabajos a partir de la cuestión del poder, los cuales presentan dos grandes problemáticas. El primero de ellos se refiere a la tierra, la construcción de territorios y las territorialidades de los distintos actores. La lectura de

\footnotetext{
${ }^{1}$ Los encargados de reunir los trabajos, lo hicieron en el marco de las X Jornadas Nacionales y II Internacionales de Investigación y Debate/II Encuentro Sudamericano de Estudios Agrarios el cual fue organizado por el Centro de Estudios de la Argentina Rural (CEAR) de la Universidad Nacional de Quilmes y el Centro de Ciencias Humanas de la Universidad Federal del Estado de Rio de Janeiro, donde los ejes que se discutieron en esa ocasión fueron las estrategias y el poder en el mundo rural en América Latina entre 1850 y 2010.
} 
estos trabajos nos posibilita conocer cómo se llevó adelante el proceso de ocupación y distribución del suelo en distintos lugares de Latinoamérica, como así también identificar los distintos movimientos sociales campesinos e indígenas en contra de empresarios quienes por diversos medios buscan acaparar nuevos territorios (Secreto, 2013: 19-38). Asimismo este tipo de relaciones nos permite entender las distintas estrategias llevadas adelante por los grandes productores y medieros por el uso del suelo y el agua, escenario agrario conflictivo y particular que debe ser comprendido y analizado en sus diversas variantes (Villareal, 2013: 39-56).

Por otro lado, estos casos permiten describir la política de tierras y las políticas públicas como la forma más cabal de la representación de los objetivos propuestos por el Estado, analizando las asociaciones y organizaciones de campesinos que buscan por distintos medios agilizar y ocupar la tierra (Lorenzana Durán, 2013: 57- 71). Esta relación de tierra y productores, se registra la dinámica que tuvieron los estados en llevar adelante acciones que intentaban combatir el latifundismo, perspectiva denominada visión tradicional del agro, en el marco de la caída de la producción durante la década del sesenta, en la Argentina, el gobierno del radicalismo intransigente de Oscar Allende demostrólos objetivos de modificar la realidad agraria bonaerense a partir de una reforma agraria (Magallán, 2013: 73-94).

Por último en relación a este eje, la segunda gran problemática analizada es el desarrollo de la prensa en vinculación a la cuestión agraria, a parir del caso que constituye la prensa argentina y brasileña. El primer trabajo propone el estudio de los periódicos la Opinión (1971-1977) y el semanario Opiniã (1972-1977), analizando las representaciones sobre la reforma agraria; de esta forma el cómo decir, transmitir la información y la construcción de la realidades son elementos claves a la hora de comprender el rol que tuvieron ambos periódicos. Los cuales tomaban como referencia a periódicos como Le Monde y The Time, en un período clave donde se discutía la tenencia del suelo y las posibles soluciones a esta problemática. Lo atrayente de esta investigación es el contexto político y los intereses de cada periódico en distintos países sumado a la mirada comparativa, que nos posibilita reconstruir una memoria latinoamericana donde se encuentran las huellas del poder (Poggi, 2013: 95-109).

Por otra parte, el análisis de los periódicos permite visibilizar los sectores dominantes que intentan por diversos medios conservar su poder hegemónico. La prensa es un lugar y escenario de lucha en donde se plasman las representaciones, el caso de la Revista Argentina Austral nos demuestra un discurso dominante ganadero y comercial en la patagonia. Durante el gobierno radical, esta revista fue un bastión de critica constante en torno a las acciones del gobierno nacional, esta oposición, nos demuestra una red local de intereses económicos y políticos, el cual nos remite al trabajo realizado por Elsa Barberia "Los dueños de la tierra en la Patagonia Austral", demostrando con ello la necesidad de continuar indagando sobre las redes de poder que se construyeron en los espacios subnacionales (Varela, 2013: 111-132).

El segundo eje presenta tres investigaciones referidas a educación y género, en donde podemos claramente conocer las historias de vida y diversas estrategias que 
desarrollaron el conjunto de mujeres en las ligas agrarias. Trabajo interesante que permite responder y construir una memoria de lucha en donde la mujer ha formado parte de esta coyuntura nacional (Walker Moyano, 2013: 135-153). En relación a esto debemos comprender el rol del estado en relación a las políticas públicas para la preparación al mundo laboral rural. Tanto los programas como las instituciones formales nos demuestran un interés por parte de las instituciones internacionales y el gobierno nacional y provincial de especializar el trabajo, en este caso las experiencias demostradas con las escuelas que estaban insertas en el programa de Expansión y Mejoramiento de la Educación Técnica Agropecuaria, E.M.E.T.A (Leguizamon, 2013: 155-174), como aquellas que se encontraban en la escuela de Santa Catalina durante el primer peronismo, rescatan acciones llevadas desde el estado para promover la colonización y la capacitación de los habitantes de las diferentes colonias (De Marco, 2013: 175-195).

El tercer eje, discute la conformación del cooperativismo y corportavismo, aquí se encuentran reunidos cinco trabajos los cuales demuestran las diversas relaciones que se produjeron en América Latina con las distintas cooperativas y asociaciones. Estas investigaciones describen las dinámicas del tercer sector brasileño y argentino. En el primer caso la investigación presentada destaca las relaciones que se conforman durante la década del '30, donde evidenciamos el protagonismo del estado a la hora de consolidar las cooperativas en Brasil (Regina de Mendonça, 2013: 199-215). Por su parte, los estudios referidos a la Argentina, nos permite comprender cómo las asociaciones de tipo sociedades y cooperativas tuvieron y tienen un lugar central en el desarrollo histórico. En este caso se destacan cuatro investigaciones que presentan distintas realidades agrarias como la que analiza el funcionamiento de la Sociedad Rural de Chascomus durante el primer peronismo, haciendo un gran balance sobre el comportamiento de los actores rurales (Salomón, 2013: 217-235). Además de este trabajo, debemos considerar el aporte que han realizado las producciones referidas al cooperativismo en regiones marginales, tales como Misiones y Chaco, en ambos casos se desarrolla las características de su formación junto con los principales inconvenientes que tuvieron en su contexto político y económico (Moglia, 2013: 237-254; Rodríguez, 2013: 255-272; Bageneta, 2013: 273 289). Cada uno de los trabajos demuestra lo importante que es continuar analizando este tipo de asociaciones dado que identificamos en primer plano los propósitos de los sujetos agrarios.

De esta forma la compilación demuestra un sólido conjunto de investigaciones originales que presentan y dejan expresa la necesidad de analizar el mundo rural desde una perspectiva social en donde las vinculaciones que realiza cada actor están entrecruzadas por redes de poder. Visibilizar este entramado permite hacer una lectura densa de un pasado lejano y próximo el cual nos demanda nuevas miradas para comprender los diversos espacios sociales.

Adrián Almirón

\footnotetext{
" Doctor en Humanidades y Artes con mención en Historia. IIGHI-UNNE/CONICET. almiron.historia@gmail.com
} 